\title{
Model-building for group decision support: Issues and alternatives in knowledge elicitation
}

\author{
Jac A.M. Vennix \\ Faculty of Social Sciences, Department of Gamma Informatics, Utrecht University, \\ 3508 TC Utrecht, Netherlands
}

\author{
David F. Andersen, George P. Richardson, John Rohrbaugh \\ Graduate School of Public Affairs, State University of New York at Albany, Albany, NY 12222, USA
}

Received October 1990; revised May 1991

\begin{abstract}
System dynamics models are often created using multiple streams of information including quantitative data, written records, and information contained in the mental models of both individuals and groups. While qualitative sources of information are widely recognized as important in all stages of the model-building process, little systematic research has been completed on how best to elicit and map this knowledge from groups of experts. In this article, we survey the existing literature on mapping and eliciting knowledge for system dynamics modeling and also explore the literature in the broader fields of cognitive psychology and small group processes. Special attention is paid to new software advances to support these processes. Two case studies illustrate how these knowledge-eliciting techniques can be used to support the construction of computer simulation models.
\end{abstract}

Keywords: Computer supported cooperative work; group facilitation; group decision support systems; knowledge elicitation; system dynamics; mental models

\section{The problem}

The topic of group decision support has grown rapidly in interest over the last decade. In the literature several types of group support systems (Nunamaker et al., 1989) are discussed, varying from collaborative writing to computer-supported negotiation to decision making (cf. Johansen, 1988; Nunamaker, 1989; Lee et al., 1988; Reagan-Cirincione and Rohrbaugh, in press). In this article we will focus on building computer simulation models with client groups as an activity to support decision making in management teams. We take the system dynamics model-building approach as an example, since system dynamics modelers have done modeling with client groups for more than a decade (cf. Roberts, 1977;
Randers, 1977; Stenberg, 1980; Weil, 1980, 1983; Richmond, 1987).

System dynamics modelers typically rely on multiple, diverse streams of information to create and calibrate model structure. Such streams include quantitative data, written records, and information contained within the mental models of key actors in a system. Commonly, the techniques for drawing out germane and accurate information from these mental models are informal and highly intuitive. Accessing the most productive source and information for model-building, the minds of experts and actors in the system, is largely an art. Rarely does the academic preparation of modelers include training or exposure to academic literature that helps to build formal skills in eliciting information for model-building. 
But practitioners know that the arts of knowledge elicitation and mapping are subtle, and can be particularly complex when the modeling process calls for drawing information out of groups of people rather than individuals.

In other fields more or less related to modeling and decision support, there already exists considerable literature that casts light on the modeler's information-gathering task. And increasingly, a number of system dynamics practitioners have begun to explore variations on the intuitive model development process described in the literature (Randers, 1977; Stenberg, 1980; Weil, 1980, 1983). This article explores these developments in an effort to push forward our understandings of productive processes for eliciting knowledge for the purpose of model-building. We will focus on a number of important issues and present several alternatives involved in eliciting and mapping knowledge for model-building with management teams. After having discussed these issues, we will present two recent cases showing the state of the art in eliciting and mapping knowledge in system dynamics model-building. As an organizing framework for our discussion we will first present the steps in the construction of a system dynamics model and show the various kinds of information needed to build a model.

\section{The model-building process: types of tasks to be supported by client groups}

Richardson and Pugh (1981) define seven stages in building a system dynamics model: problem identification and definition, system conceptualization, model formulation, analysis of model behavior, model evaluation, policy analysis, and model use or implementation. Roberts et al. (1983) use an almost identical set of six stages to organize their pedagogical approach. Table 1 summarizes the steps and stages in model-building.

As can be seen from this table, the process of constructing a computer simulation model involves a wide variety of conceptual activities. These range from 'brainstorming' variables to be included or excluded from the model's boundary to determining specific parameter values to identifying the important feedback loops within a system. Psychologists specializing in cognitive
Table 1

Stages and steps in model-building

\begin{tabular}{ll}
\hline Stage & Steps \\
\hline Problem & $\begin{array}{l}\text { define time horizon } \\
\text { identify reference modes } \\
\text { define level of aggregation } \\
\text { define system boundaries } \\
\text { establish relevant variables } \\
\text { determine important stocks and flows } \\
\text { map relationships between variables } \\
\text { identify feedback loops } \\
\text { generate dynamic hypotheses } \\
\text { develop mathematical equations } \\
\text { quantify model parameters } \\
\text { check model for logical values } \\
\text { conduct sensitivity analyses } \\
\text { validate model } \\
\text { analysis/evaluation }\end{array}$ \\
conduct policy experiments \\
policy analysis
\end{tabular}

processes, however, have commonly distinguished between three general types of tasks: eliciting information, exploring courses of action, and evaluating situations (Hackman and Morris, 1975; Morris, 1966; Hackman, 1968; Bourne and Battig, 1966; Simon, 1960). Different phases of the modeling process emphasize different combinations of these three types of psychological tasks. Hence, knowledge-eliciting approaches for one phase may not be appropriate for another.

\section{Eliciting information}

The terms 'brainstorming' or 'divergent thinking' have often been applied to some conceptual behavior of this sort. In the system dynamics model-building process, this type of thinking is often most necessary in the problem definition or model conceptualization phases where an individual or a group is attempting to determine what factors or variables to include or exclude from a system's boundary, or in the model evaluation phase where the group is brainstorming how to design or evaluate a model's performance. In addition, this eliciting process may also be evoked during some phases of the model formulation process where several different formulations need to be considered.

There is considerable evidence that work on elicitation tasks in group settings should be performed by noninteracting, 'nominal' groups, rather than with full discussion and exchange of 
ideas in an open forum (Lamm and Trommsdorf, 1973). The quantity and diversity of ideas tend to be greater in nominal groups. The greater interplay of ideas that can occur in discussion groups appears to be outweighed by tendencies of interacting groups to inhibit divergent production.

\section{Exploring courses of action}

Solutions to problems are discovered through devising, specifying, or following combinations of procedures that might achieve specific objectives. Problem solving within the context of the system dynamics modeling processes involves tasks such as specifying the feedback paths to be included within a model or devising a specific rate formulation.

Often referred to as a form of "convergent thinking', such group activity is thought to be at its best when organized and highly systematized. However, the paucity of rules specifying what constitutes key information or what is the essential information to be structured typically makes this type of a task most puzzling to organize for a group. Deep knowledge of the system being studied and the nature of the model-building task at hand is necessary to structure appropriate group activities. However, once the task has been structured we have found that a facilitator with generic group facilitation skills is often better at directing the group process than a skilled modeler. Most often, both roles are required to manage properly this class of cognitive tasks.

\section{Evaluating situations}

The most common modes of evaluation are judgment (assessing individuals, objects, or events one at a time on some scale) and choice (selecting one or more individuals, objects, or events from a set). In the process of building system dynamics models, evaluation includes tasks such as selecting parameters, assessing the validity of model output, assessing the performance of various policies, choosing between alternative structural formulations, or choosing which policies to investigate within the context of model situations. In both judgment and choice, evaluation is based on the explicit and/or implicit use of one or more cues that inform the group in completing its task. Judgment and choice processes do not necessarily lead to the same conclusions, however. Preferences expressed in one mode may be reversed in the other (Lichtenstein and Slovic, 1971, 1973). Hammond et al. (1977) and Rohrbaugh (1981) have proposed using specific techniques such as social judgment analysis to support evaluation tasks. Finally, as discussed in one of the cases below, multiattribute utility theory provides a framework for evaluation competing options, such as outcomes of policy simulations, on multiple criteria.

\section{Some basic results from group process research}

While different types of cognitive processes are involved in various stages of the model-building process, Forrester (1980) has noted that a wide variety of sources of knowledge must be incorporated into the model-building process. These sources of knowledge range from quantitative data to written records to the mental models of both individuals and of groups. Our emphasis here is strictly on eliciting knowledge from groups. Richardson et al. (1989) have surveyed qualitative methods for dealing with written documents and individual interviews, questionnaires, and workbooks.

McGraw and Harbison-Briggs (1989) have demonstrated that the type of knowledge and the quality of judgements acquired from experts in a group setting differ from information obtained when they are questioned as individuals. Shaw (1932) found that one advantage of using groups was their ability to recognize and reject incorrect or impossible solutions and suggestions. Steiner (1972) has found that a group of experts may be better able to solve a problem that involves exploring courses of action than individuals working alone; improvement comes from subdividing the task into related tasks and matching the expertise of participants with a particular subtask. Sniezek (1990) also points out that if group members share relevant information, groups are not superior to individuals. The effectiveness of groups also seems to be correlated with group size, type of tasks, and structuredness of the group process. With larger groups, for instance, formal brainstorming techniques in nominal groups have been found to be superior to interacting groups (Lamm and Trommsdorf, 1973). Communications among 
group members decreases as the size of the group increases. Slater (1958) has found that for tasks involving decisions based on evaluation of exchanged information, groups of five or fewer are most effective. Bouchard (1969, 1972) indicates that introducing structure in group sessions drastically improves group performance. Hart et al. (1985) also point out that without structuring of tasks and group processes, participants might become frustrated and group performance rapidly decreases. In addition, in freely interacting groups there is a tendency for strong personality types or high-status persons to dominate discussions (Fox, 1987). Freely interacting groups also tend to rapidly narrow their focus on a few approaches to the problem and to concentrate on evaluation of ideas. These common defects in group process can usually and easily be overcome by a skilled group facilitator, once again underscoring the need to add generic group facilitation skills to a strong modeling team.

Given what is stated above, it is useful to make a distinction between strongly or weakly structured group sessions or workshops for modelbuilding. Less-structured group processes and discussions are the approaches used by most system dynamicists working in a consulting mode. Introduction of structure in group sessions can be related to two aspects: the tasks to be performed and the group process itself.

Structuring the tasks in model-building can be accomplished by either breaking down the modeling process into smaller sequential steps or by presenting the group with a preliminary model that can be discussed systematically one part at a time.

An example of breaking the model-building process into smaller sequential steps is Duke's technique for designing a gaming simulation. The process begins with a brainstorming session in which participants write down on small pieces of paper all kinds of concepts that come to mind when thinking about the policy problem under study. Duke (1981, p. 64) calls these little pieces of paper snowcards. The second step is to organize and classify these concepts into broader categories by removing duplicate concepts, merging similar concepts, and classifying groups of concepts The third step involves constructing a diagram of system structure using these broad categories. Differing specific small group techniques are used to support each of these small steps within a structured group workshop.

Hart et al. (1985) and Vennix (1988) present examples of structured workshops using the preliminary model approach. In this approach the modeler first designs a preliminary model and then presents it to the client, who can criticize it extensively. The client is encouraged to redesign flawed or inadequate parts of the model. Skill and judgment need to be exercised when engaging in preliminary modeling work. Too much model development without client interaction can suppress the client group's ownership and creativity in the project.

Structuring of group sessions can also relate to the group process itself. For instance, in order to decrease the dominance of certain participants and to guarantee that all participants have an equal chance to put forward their ideas one could break down the total group into smaller subgroups during the session. The ideas generated in the subgroups can be presented and discussed with other subgroups in a plenary session.

\section{Facilitator versus modeler}

Given that groups will almost always be a part of the model-building process it is important to consider the issues involved in facilitating groups, a task which diverges considerably from building a system dynamics model. Recently, system dynamics modelers such as Richmond $(1987,1988)$ and Richardson and Schuman (1987) have begun to experiment with the reference group approach (cf. Randers, 1977) by using new software products such as STELLA (Richmond, Peterson and Vescuso, 1988) to get groups of decision makers to interact more directly with a model's structure and output as the model is being developed. In his work, described in more detail below, Richardson had considerable success in separating the role of the professional modeler, who sat in the back of the room and operated a STELLA-based model being projected for review by the group, from that of a professional group facilitator who managed the group. This group facilitator was familiar with system dynamics 
modeling but brought generic group facilitation skill rather than system dynamics modeling skill to the overall group process.

\section{Hardware and software supports for knowledge elicitation}

Even as a large literature is beginning to emerge on how individuals and small groups approach problems and structure knowledge for problem solving, a variety of software packages exist for supporting individual or group brainstorming sessions. For example, MAXTHINK (IBM compatible) or MORE (Macintosh) provide a set of flexible text-processing and sorting utilities that can help both to elicit and organize verbal concepts. When projected in front of a small group, these software programs can be used to support group brainstorming, acting as a sort of infinitely flexible 'electronic flip chart'.

Shachter (1986) has developed DAVID, a modeling tool that helps to structure influence diagrams and representations of probabilistic and deterministic decisions. DAVID can be used as a software support in the conceptualization or problem definition phases of a modeling project where causal loops are being either generated or discussed by a group. DESIGN on the Macintosh can be used similarly. The potential of these software tools for model conceptualization in groups has, to our knowledge, not yet been tested.

Most system dynamics practitioners are by now familiar with STELLA as developed by Richmond et al. (1988). Developed exclusively for Macintosh machines, this very powerful modelbuilding tool allows modelers to create models at a conceptual level very different from what had been possible previously using conventional simulation languages such as DYNAMO and DYSMAP. Using STELLA, analysts work with screen-oriented icons that allow them to construct system flow charts interactively. While users respond to several prompts and queries at key decision points (usually rates and auxiliaries), the STELLA system writes equations in the background and can then execute a simulation. As the model is simulated, the software can animate on the computer screen the rise and fall of accumulations in the stock-and-flow diagram. Diehl (1988) and Richmond and Peterson (1989) have developed gaming interfaces for STELLA. Using these interfaces, modelers may create an animated game-like view of a simulation. Using these animations, users may interact directly with the simulation model, often without having to come to grips with or understand the structure of the system under study. Such a facile ability to interact with a model of course, has both positive and negative implications.

Modern versions of DYNAMO contain front end packages that allow users to interact more easily and directly with a simulation model once it has been created. Using a structured and menu-driven series of screens, users respond to a series of queries and the package creates a stream of commands much like the traditional RERUN streams that creates a new model run. Packages such as these are very useful for allowing users to interact with a model once it has been constructed. Expert modeling support is needed to construct both the model and to program the front end package.

The above software tools were designed primarily to support a single terminal or work station. It is important to note, however, that many of these software tools are being used with groups by having output projected for review and discussion by a group as a whole.

Recently, a number of sites have experimented with multiple, linked work stations or terminals designed to support knowledge elicitation. The two most well known are at the decision and planning laboratory at the University of Arizona and at Xerox Park's COLAB. Arizona has a research facility for studying the impact of automated support for planning and decision making. It is used by executives, managers, and students for planning sessions and to address complex, unstructured decision processes. As described by Nunamaker, Applegate and Konsynski (1988) the lab has been operational since March 1985 with state-of-the-art computer hardware and software used in a boardroom. Two of their software tools are used to support the process of deliberation, electronic brainstorming, and stake-holder identification and analysis. Electronic brainstorming permits participants to network using micro-computers to share comments and contributions with other participants. Comments from all participants are consolidated and an analysis support tool is used to identify common issues or cate- 
gories. This computer-based technique is adapted from manual procedures developed in association with Strategic Assumptions Surfacing and Testing as reported in Mason and Mitroff (1981).

The use of dynamic interactive media at Xerox is part of COLAB. This computer lab's purpose is to increase the effectiveness of meetings and to provide a research environment to investigate the effects of computer tools on meetings. Stefik et al. (1987) report that within COLAB a variety of tools are available to provide participants with a coordinated interface, enabling them to interact cooperatively. COLAB tools support simultaneous action, allowing group members to work in parallel on shared objects. Conflicts (e.g., more than one member attempting to act on the same image) are handled by a busy signal. There are a variety of software tools to extend the uses of COLAB.

Both the Arizona and the Xerox labs can be seen as experimental mechanisms for eliciting the group knowledge useful in model-building. However, their effectiveness in designing models is as yet to be assessed, since these facilities have never been used to support the construction of system dynamics models.

\section{Guidelines for structuring the knowledge elicita- tion process}

Given that such a wide variety of knowledge elicitation techniques and approaches exist, the key question becomes knowing how to approach the elicitation process and when to use which technique. We have identified five factors that help the modeler to select appropriate knowledge elicitation techniques: the phase in the modelbuilding process and the type of task being performed, the number of persons involved in the process, the purpose of the modeling effort, the time available for participants, and finally the costs involved in using various techniques.

The recommendations that follow are still quite tentative. How to combine these five critical factors in selecting appropriate knowledge elicitation techniques remains more of an art than a science. However, the guidelines suggested here do suggest an important checklist of items that always deserve attention in client-oriented modeling.

Phase of the modeling process and type of task. The phase of the model-building effort interacts subtly with the type of cognitive task being undertaken in determining what type of knowledge elicitation techniques are most appropriate in a given specific situation. Hence in each phase of the modeling process various techniques might have to be employed in combination, depending on the type of task that has to be performed.

From a psychological point of view, eliciting, exploring, and evaluating tasks need to be approached very differently. As a general rule of thumb, eliciting tasks, requiring divergent thinking, can best be performed by individuals alone or in nominal noninteracting groups. Performing these tasks in the context of well-structured group interactions will actually decrease the quality of group versus individual performance.

Evaluation tasks, on the other hand, can best be performed in structured group sessions. The literature on evaluation, whether it involves individual or group evaluation of options, events, or alternative formulations, is quite well-developed. Specific techniques such as the Delphi technique (Linstone and Turoff, 1975), multiattribute utility theory (Edwards and Newman, 1982), social judgment analysis (Hammond et al., 1975) and nominal group techniques (Huseman, 1973) have well-developed theoretical underpinnings and have been well-explored in experimental settings.

The exploring (problem solving) task is both most central in the model-building process and least well-developed in the psychological literature. Some evidence suggests that well-trained or knowledgeable individuals can perform as well as or even better than groups. Simply put, a welltrained model builder can do as well as a group of model builders in tasks such as proposing formulations or designing feedback structures. Involving a group may have an apparent purpose of designing model structure, but have as a real purpose developing understanding of the system under study or of the model-building process (see: Purpose of modeling effort). One way to improve the difficult exploring tasks involved in model-building is to include an experienced group facilitator with significant understanding of model-building in the project team. 
Purpose of the modeling effort. The process of eliciting and mapping knowledge to build system dynamics models is not a straightforward one. Rather it is iterative - through successive cycles of refinement the ultimate model gradually appears. So knowledge elicitation and mapping is not just simply a process of uncovering a fixed body of knowledge and representing it. Modelbuilding induces learning in participants as their mental models are reshaped by discussion and interaction. This iterative view of the knowledge elicitation process has profound implications for the methods and techniques to be used. In addition to written documents and individuals as a source of knowledge, modelers will have to employ methods that allow interaction and discussion in order to improve mental models and to clarify a problem. Hence, in modeling policy problems, groups as a source of knowledge will almost always have to be included in the modeling process.

Number of people. The number of people involved in the modeling project will dictate the appropriate knowledge elicitation techniques because of two factors. First, the smaller the number of people involved, the more unstructured the techniques may be. If a large number of people are involved (as in public policy modeling), the approaches will have to be more structured to prevent discussions from getting out of hand. Second, as more people become involved in the modeling process, it becomes necessary to use labor-saving techniques such as questionnaires, workbooks and structured workshops (Vennix, 1990). Structured workshops are especially valuable because they can be repeated several times and the results from several workshops accumulated over time.

Particularly with larger groups the use of software support may allow the group to interact more effictively and may speed up the process of model-building.

Time available for participant discussion. A simple but powerful criterion for determining what knowledge elicitation techniques to use is the amount of time the management team or reference group can spend on tasks. The less time they have available for active participation in the modeling effort, the more the process will have to be carefully structured and prepared. For example, a group might begin with a preliminary model rather than attempt to develop a model from scratch.

A second critical factor centers on how far along the group is in its thinking about the problem. If they are just starting to address issues, then overstructuring the problem definition may be inappropriate. If the issues are complex, then divergent thinking will be best encouraged by a blend of approaches that ask individuals to brainstorm in isolation, and then to share ideas and contemplate issues in group discussion.

Cost. Finally, the costs associated with the various techniques must be carefully factored into the selection of knowledge elicitation and mapping techniques. Costs include participant costs (usually in terms of time devoted to the modeling process) as well as the costs of time for the modeling team. Usually costs (both monetary and time costs) will be negotiated at the beginning of a project and the modeler's task will be to select the best techniques given cost constraints. Hence cost considerations are most important at the stage where a modeling contract or agreement is being designed.

Overall the conclusion must be that in such complex processes as eliciting knowledge in the model-building process, one cannot rely on the use of one single technique. Rather one will have to employ hybrid techniques (Nutt, 1984), i.e. a useful combination of approaches and techniques that will support each of the tasks in each of the stages as optimally as possible.

In the next sections we will present a few examples showing the use of hybrid techniques for knowledge elicitation in model-building. The first example aims at eliciting knowledge for building a conceptual model of the Dutch Health Care system (cf. Vennix et al., 1988). The techniques which are used to elicit knowledge from relevant participants have been chosen in such a way that they carefully fit the various tasks and stages in eliciting the necessary knowledge. The second example is on model-building in medical malpractice insurance (Richardson and Schuman, 1987; Richardson and Senge, 1989). Here too, a combination of system dynamics modeling with formal multiattribute utility techniques (Edwards and Newman, 1982) was used to evaluate the effects of a variety of policy runs. Moreover, this case clearly shows the uses of software and the beneficial effects of separating the role of the 
facilitator and the modeler in working with groups.

\section{Example 1: Modeling Dutch Health Care}

The model-building process of Dutch Health Care was conducted to provide more insight into the factors and processes underlying increasing health care costs (cf. Vennix et al., 1988).

The elicitation process is started by a project group that designs a preliminary model of the problem. Next a policy delphi procedure (Linstone and Turoff, 1975; Dunn, 1981) is employed to have a number of experts (60) in the field comment on this preliminary model. The first delphi cycle consists of a questionnaire, dealing with binary relationships in the model, i.e. relationships between two variables. The second cycle builds on the results of the first and takes the process one step further by having experts criticize more complex submodels. Here a so-called 'workbook' is used to elicit knowledge from the expert group. The third cycle consists of a structured workshop, in which a number of experts can thoroughly discuss parts of the conceptual model. The first two delphi cycles serve a focusing function: they eliminate those elements from the discussion on which there is a great deal of consensus in the expert panel. The sequential stages in the elicitation process are summarized in Figure 1.

The preliminary model was designed by the project group, consisting of two persons from the client organization and two system dynamics modelers. The model was based on available literature and insights within this group and was used as the basis for the delphi cycles. A group of approximately 60 persons (e.g. general practitioners, scientific researchers, financial planners, hospital managers), of which 90 percent responded, was consulted in the first cycle.

The questionnaire contains questions on binary relationships, i.e. relationships between two variables. The project group subdivided the questionnaire into a number of sections, each dealing with one of the important decisions in the health care system (e.g. prescriptions, consultations). These form the 'dependent variables'. In each section a number of statements were presented

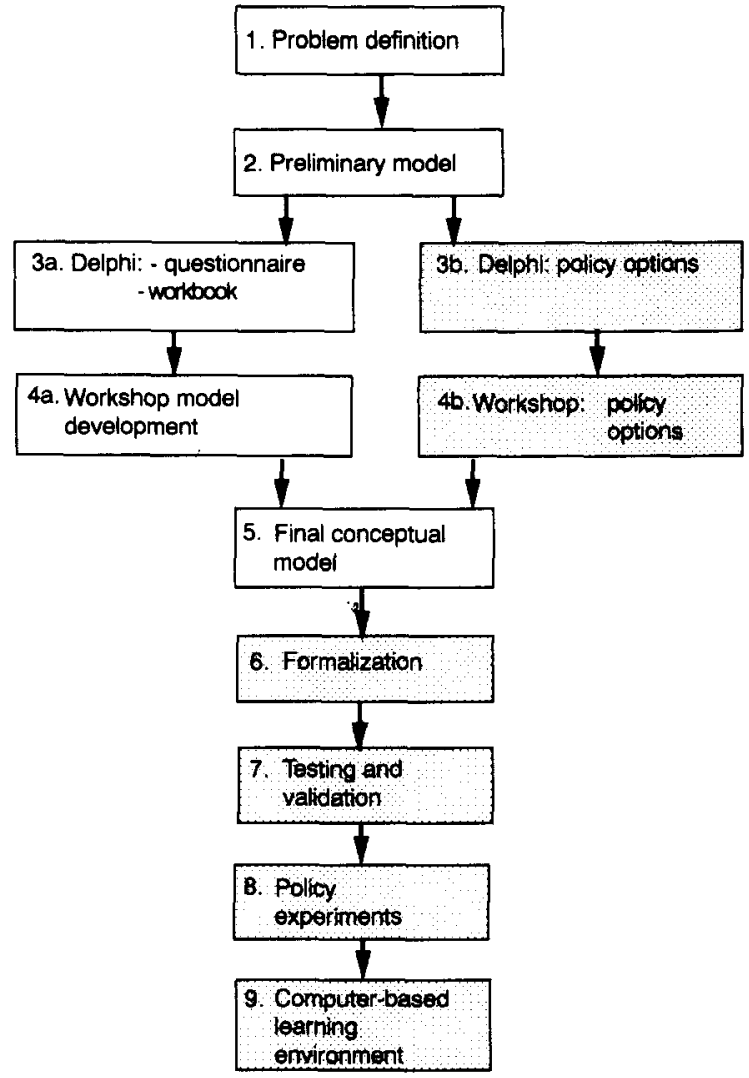

Figure 1. Phases in the model-building project

describing a relationship between this dependent' variables and some independent variable. For instance, in the section 'prescriptions by general practitioners' one of the statements is:

'The heavier the workload of a general practitioner, the higher his number of prescriptions'.

Participants were asked to state whether they 'agreed fully', 'agreed partially', or 'disagreed fully' with the statement. However, the project group was primarily interested in uncovering causal arguments from the participants' mental models, particularly those which were not included in their preliminary model. To extract these causal arguments they asked the respondent after each statement to indicate why one did or did not agree with the statement. Content analysis with regard to the answer to the "why questions' revealed a number of interesting things. For instance, new concepts that might be included in a causal relationship, thereby clarifying it. Each section in the questionnaire, focusing on one 'dependent' variable, thus contained a number of these statements together with "why ques- 
tions'. In addition, at the end of each section the respondent was asked to add variables not yet mentioned, which they perceived to affect the dependent variable. Finally, in each section the respondent was asked to name the three independent variables that he considered to have the largest effect on the dependent variable.

In the second cycle of the delphi the project group switched to a workbook which was based on the results of the questionnaire. It enabled the respondent to focus on sets of interrelated variables instead of only binary relationships. Second, the workbook was also used as a means to prepare participants for the workshop. A subset of 18 respondents was selected from the sixty respondents who participated in the first cycle.

The workbook contained four submodels. These submodels were designed by the project group, based on the preliminary model and the results of the questionnaire. The submodels were gradually introduced into the workbook using causal diagrams as an aid for the participant. At regular intervals the respondent was asked to comment on the argument in the workbooks and to indicate in the final diagram of the submodel which parts one did not agree with by circling these parts. The completed workbooks were sent to the project group one week before the workshop. The final step in this approach involved two structured four-hour workshops (with 9 participants each) in which participants discussed the submodels in more depth. The entire session was broken down in four stages: introduction (half hour), subgroup activities (one hour), plenary session ( $1 \frac{1}{2}$ hours) and finally evaluation (half hour).

A few aids were used to structure the discussions in the subgroups. First of all, each of the members of the group was assigned a role. For instance, one person took notes and presented the results in the plenary session, while another person was responsible for time management. Second, diagrams were copied from the workbook and by using three different colors indicated which of the three persons had commented on what parts of the submodel in his workbook. The colored parts of the submodels had to be discussed first during the subgroup meeting. Participants were asked to make changes in the diagrams according to the results of their discussions. In order to accomplish this task, they were provided with the relevant diagram of the work- book, which was put on the table in the subgroup room. During the discussions they employed this diagram as a kind of scribbling paper to make changes according to their discussions, by removing or adding variables and/or relationships between variables.

After having completed their discussions, one person was responsible for integrating the final changes into a large diagram, hanging on the wall in the subgroup room. This large diagram was then put on the wall in the plenary session room to assist the discussion during the plenary session. On the basis of this diagram the spokesperson of a subgroup was given ten minutes to explain the results of the discussions and the changes made in the submodel by the group. During the next twenty minutes the other subgroups were permitted to ask questions and comment on the results. The same procedure was used in discussing the results of the activities in the other two subgroups. The total time for plenary discussion was thus $1 \frac{1}{2}$ hours. Participants in both the small groups and the plenary sessions were quite involved and there seemed consensus on a number of issues.

\section{Example 2: The medical malpractice insurance decision conferences}

The New York State study began in the fall of 1987 at the request of the State Insurance Department. The Department, headed by the State Insurance Commissioner appointed by the governor, has overall responsibility for the proper functioning of insurance programs operating in the state. Actuaries in the Department check that rate increases requested by insurers are justified, and they monitor the financial health of insurance companies. Both of these duties are intended to serve the public interest: if rates are excessive, then the public overpays, and if rates are too low and companies move toward insolvency, then the public will not get what it has paid for - insured parties will not be covered and victims will not receive just compensation.

Legislation passed in 1985 regulating doctors' premiums for medical malpractice insurance was due to expire in April 1988. The Legislature asked the State Insurance Department to provide 
advice to avert an impending crisis. Before the 1985 legislation, premium increases on the order of $40-50$ percent demanded by the insurance companies were so large that doctors threatened to cut back services. Some mothers-to-be found it almost impossible to find an obstetrician willing to care for them. The crisis was averted when the Legislature passed a bill limiting increases in doctors' premiums to 14 percent the first year and 9 percent for each of the next two years. Recognizing that such low increases would not match the increasing costs of the insurance companies, the Legislature also decreed that no insurer would be declared insolvent and be barred from selling malpractice insurance in the state during these years. Indeed, such a provision was necessary: by the Insurance Department's later reckoning, the five New York State medical malpractice insurers were statistically insolvent by 1986 with assets below projected liabilities by more than 2 billion dollars.

Now that the three years were up, the Legislature wanted a more permanent solution. The State Insurance Company contracted with members of the faculty of the Rockefeller College to run three decision conferences designed to develop consensus within the department about more than forty policy options they were considering. To provide the greatest decision support, the Rockefeller College team decided to include the development of a system dynamics model to project the implications of various policy options.

A model reference group was formed (Stenberg, 1980) and met three times over a six-week period to discuss model structure and the focus of the modeling effort. The group consisted of actuaries and analysts in the Insurance Department and an outside consultant, and included all of the people who would be involved in writing the final report to the Legislature, under the signature of the Commissioner. In the most productive of these reference group meetings, the roles of group facilitator and model-builder were separated, enabling the modeler to concentrate solely on gathering, interpreting, and reflecting back information for the model-building process.

The decision conferences were designed to evaluate a maze of more than forty policy options the Department, its consultants, and the Legislature wanted to consider. The conferences were facilitated by professionals in group process and decision support from the Rockefeller College, and were computer-aided by the use of system dynamics simulations and multiattribute utility analyses projected for all to see and reflect upon.

The initial list of policy options given by the Insurance Department served to focus the modeling effort; the data for reference models for the dynamic model came part way through the modeling effort. Because of the time constraints leading to the first decision conference at which the system dynamics model would be used, the model was developed to address a small subset of the policy options facing the State Insurance Department. The model (Schuman and Richardson, 1987; Richardson and Senge, 1989) consisted of about 300 active equations ( 22 levels).

The initial policy options being considered emphasized financial solutions, so the model was more detailed on the financial side and had only a rudimentary treatment of the processes underlying the dramatic growth in settlement awards. It was, in fact, an outcome of the fall decision conferences that policies that ignore the growth in awards would work only in the short run, if they worked at all. Confidence in the model in the decision conferences was the result of confidence in the model reference group that contributed to its formulation, the close dynamic fit between the model and historical time series, and the fact that participants could give real-system explanations for model behavior in the policy simulations shown.

The most important simulation shown in the first decision conference, at least in terms of its effect on the thinking of the group, was a simulated test of switching the malpractice insurance system to a pay-as-we-go system. The idea is seductively attractive: in the current scheme, the system operates as a true insurance system, in which a stock of assets is required to cover the stock of projected liabilities. In a pay-as-we-go system, the stock of assets would only be required to cover the flow of payments over some number of years (as with social security in the United States). Switching to pay-as-we-go for the malpractice insurance system would immediately and dramatically drop the asset requirement for insurers and cure the insolvency problem. In addition it would allow doctors' premiums on the average to drop significantly. It looks like a winwin policy. 
The simulation shown to the group altered that perception. In the simulation, beginning in 1988 the system switched to a policy of assets required to cover a year's flow of malpractice payments, and the requirements of insurance companies were given much greater weight in the premium-setting process. The result is immediate solvency for insurers, which lasts beyond the year 2000 but turns into insolvency and then bankruptcy within five more years. Doctors' premiums actually decrease and stay below their 1987 levels until 1992. The system is still driven, however, by $20 \%$ annual growth in settlement awards. Trying to come closer to the premiums required to keep insurers solvent results in faster premium growth: the average doctor premium actually exceeds the base run value by 1995 . Pressures to hold down the increases accumulate and finally can not be ignored. The system collapses about the same time as it did in the base run.

Seeing that the policy gains only about eight years of premium relief, and hearing the explanations of that results from the actuaries around the table at the decision conference, the state insurance commissioner ruled out the pay-as-we-go policy option. It was not discussed again and was dismissed in the policy recommendations finally sent on to the Legislature (NYSID, 1988, 163171).

To focus the decision group on the dynamics of their detailed policy options, participants were given graphs of the six time series from 1975 to 1986 and asked to complete them to 2015 for every policy option they considered. Those graphs and the increasingly sophisticated mental models of the participants formed the basis for the detailed multiattribute utility analyses that structured the group's evaluation of policy options. In the multiattribute utility evaluations, the group identified six constituencies and generated more than forty criteria those constituencies would use to evaluate policy options. Most of the discussion in the decision conferences focused on generating policy options and evaluating them in detail on these criteria. The simulation model was revised as necessary during the conferences and used at the close of each conference to test the favorite policy mix.

One month before their April 1988 report was due, the Insurance Department held a final decision conference to check their recommendations in a structured setting. A revised simulation model was used to predict aggregate impacts of three policy sets, one developed by the Department and two others developed by outside consultants. The policy recommendations were extremely detailed and complex, and the model was able to represent them only approximately. The simulations suggested that only the Department's own proposals were adequate to prevent the insolvency from getting worse. The day-long discussions and policy evaluations, again primarily aided by multiattribute utility analyses, reinforced the Department's thinking and convinced them to go ahead with their proposals to the Legislature.

The Department's subsequent report to the New York State Legislature was a book of more than 240 pages describing the problem and its history, why action was necessary as soon as possible, what options were available and what outcomes they were likely to produce, and an outline of the processes the Department went through to produce its recommendations. The Department's preferred policy option package contained 29 detailed proposals in four categories: ways to decrease malpractice, spreading the costs of the system across a wider base, tort changes, and procedural changes. The proposals reflected the Department's thinking about the political acceptability of the total package as well as the efficacy of its elements.

Faced with time running out on the 1985 legislation, the complexity of the problem and the recommendations, the observation that none of the insurers were in danger of immediate bankruptcy, and the possibility that further research might suggest a better solution, the Legislature passed continuing Legislation that simply extended the 1985 law another three years. This potentially disappointing result was probably appropriate: much work remains to be done to develop deep understandings about the systemic causes of the problems and to identify focused, high-leverage policy options that should be adopted.

\section{Summary and conclusions}

A rich body of theoretical and experimental work already exists on how to elicit and map qualitative knowledge that resides in the mental 
models of individuals and groups. An interesting array of software products is beginning to emerge to support such model-building exercises. Finally, several interesting experiments such as the COLAB at Xerox and the Group Decision Support Laboratory at the University of Arizona are attempting to provide more advanced computerbased support to knowledge elicitation and mapping processes, especially the thorny problems associated with exploring courses of action and problem solving.

Increasingly, this body of research is being integrated into system dynamics practice. A number of researchers have come to realize that the careful structuring of group process to match the type of cognitive task facing the group can greatly enhance the productivity of the group. And since various stages of the model-building process involve quite different psychological processes, various researchers have begun to conclude that group techniques appropriate for one phase of model-building and knowledge elicitation may not be appropriate for another phase. We have presented a number of heuristics and rules of thumb for diagnosing what type of group process might be best suited to what model-building task.

However, knowledge elicitation to support model-building is still much more of an art than a science. While isolated pockets of best practice have emerged guided by good modeling intuition, these results are not generalizing to the modelbuilding community as a whole. It seems clear that those who write about the system dynamics modeling process are not paying close attention to developments in other fields that hold great promise for improved system dynamics practice. Similarly, those most experienced in the art of modeling appear not to have the time or inclination to write down the lessons that they have learned from years of practice working on knowledge elicitation and mapping.

As a result, the critical phases of problem definition and model conceptualization appear to be arrested at the point where they remain true art forms. Simply put, systematic research is not being conducted that will advance our understanding of how modelers and management teams or reference groups do or ought to interact in the model-building process. This lack is all the more disturbing because psychologists, ethnographers, management scientists, and software engineers working in fields closely related to system dynamics are making progress in precisely these fields. The field of system dynamics needs to begin the work of formulating rigorous research programs that get at general rules helping to make more precise and less artful the process of eliciting and mapping knowledge.

\section{References}

Bouchard, T. (1969), "Personality, problem solving procedure and performance in small groups", Journal of Applied Psychology 53, 1-29.

Bouchard, T. (1972), "A comparison of two group brainstorming procedures", Journal of Applied Psychology 56, 418421.

Bourne, L.E., and Battig, W.F. (1966), "Complex Processes", in: J.B. Sidowski (ed.), Experimental Methods and Instrumentation in Psychology, McGraw-Hill, New York.

DESIGN, (1988), Meta Software, 150 Cambridge Park Drive, Cambridge, MA 02140. Reviewed in Mac User, April 1988.

Dewey, J. (1910), How We Think, Heath, New York.

Diehl, E.W. (1988), Microworlds Creator, Microworlds Inc., Cambridge, MA.

Duke, R.D. (1981), “A paradigm for game design", in: C.S. Greenblat and R.D. Duke (eds.), Principles and Practices of Gaming-Simulation, Sage, Beverly Hills, CA.

Eden, C.S. Jones, and D. Sims, (1983), Messing about in Problems: An Informal Approach to their Identification and Management, Pergamon Press, Oxford.

Edwards, W., and Newman, J.R. (1982), Multi-Attribute Elaluation, Sage, Beverly Hills, CA.

Forrester, J.W. (1961), Industrial Dynamics, MIT Press, Cambridge, MA.

Forrester, J.W. (1980), "Information sources for modeling the national economy", Journal of the American Statistical Association 75/371, 555-574.

Forrester, J.W., and P.M. Senge, (1980), "Tests for building confidence in system dynamics models", System Dynamics, TIMS Studies in Management Science, Vol. 14, Elsevier, Amsterdam, 209-214.

Fox, M. (1987), Effective Group Problem Solving, Jossey-Bass, San Francisco, CA.

Galtung. J. (1969), Theory and Methods of Social Research, Columbia University Press, New York.

Gardiner, P.C., and Ford, A. (1980), "Which policy run is best and who says so", System Dynamics, TIMS Studies in the Management Sciences, Vol. 14, Elsevier, Amsterdam, 241-257.

Graham, A.K. (1980), "Parameter estimation in system dynamics modeling", in: J. Randers (ed.), "Elements of the System Dynamics Method", MIT Press, Cambridge, MA, $143-161$.

Hackman, J.R. (1968), "Effects of task characteristics on group products". Journal of Experimental Social Psychology 4. 162-187. 
Hackman, J.R., and Morris, C.G. (1975), "Group tasks, group interaction process, and group performance effectiveness: A review and proposed integration", in: L. Berkowitz (ed.), Advances in Experimental Social Psychology Vol. 8, Academic Press, New York.

Hammond, K.R., Stewart, T.R., Brehmer, B., and Steinmann, D.O. (1975), "Social judgment theory", in: M.F. Kaplan and S. Schwartz (eds.), Human Judgment and Decision Processes, Academic Press, New York.

Hammond, K.R., Rohrbaugh, J., Mumpower, J.L., and Adelman, L. (1977), "Social judgment theory: Applications in policy formation", in: M.F. Kaplan and S. Schwartz (eds.), Human Judgment and Decision Processes in Applied Settings, Academic Press, New York.

Hart, S., Boroush, M., Enk, G., and Hornick, W. (1985), "Managing complexity through consensus mapping: Technology for the structuring of group decisions", Academy of Management Review 10/3, 587-600.

Hoogerwerf, A. (1984), "Beleid berust of veronderstellingen: De beleidstheorie", (Policies are based on assumptions: The policy theory) Acta Politica 4, 493-531.

Huseman, R. (1973), “The role of nominal groups in small group communication", in: R.C. Huseman, D.M. Logue and D.L. Freshley (eds.), Readings in Interpersonal and Organizational Communication, second edition, Hollbrook, Boston, MA

Hyman, H. (ed.) (1954), Interviewing in Social Research, University of Chicago Press, Chicago, IL.

Johansen, R. (1988), Groupware: Computer Support for Business Teams, Free Press, New York.

Lamm, H., and Trommsdorf, G. (1973), Group versus individual performance on tasks requiring ideational proficiency (brainstorming): A review", European Journal of Social Psychology 3, 361-388.

Lee, R.M., and McCosh, A.M., and Migliarese, P. (1988), Organizational Decision Support Systems, North-Holland, Amsterdam.

Lichtenstein, S., and Slovic, P. (1971), "Reversals of preference between bids and choices in gambling decisions", Journal of Experimental Psychology 89, 46-55.

Lichtenstein, S., and Slovic, P. (1973), "Response-induces reversals of preference in gambling: An extended replication in Las Vegas", Journal of Experimental Psychology 101, 16-20.

Linstone, H., and Turoff, M. (1975), The Delphi Method: Techniques and Applications, Addison-Wesley, Reading, MA.

Mason, R., and Mitroff, I. (1981), Challenging Strategic Planning Assumptions, Wiley, New York.

McGraw, K.L., and Harbison-Briggs, K. (1989), Knowledge Acquisition: Principles and Guidelines, Prentice-Hall, Englewood Cliffs, NJ.

Moore, C.M. (1987), Group Techniques for Idea Building, Sage, Beverly Hills, CA.

Morris, C.G. (1966), "Task effects on group interaction", Journal of Personality and Social Psychology 4, 545-554.

Nunamaker, J.F., Applegate, L.M., and Konsynski, B.R. (1988), "Computer-aided deliberation: Model management and group decision support", Operations Research $36 / 6,826-848$.

Nunamaker, J.F. (1989), "Experience with and future chal- lenges in GDSS, preface", Decision Support Systems 5, $115-118$.

Nunamaker, J., Vogel, D., and Konsynski, B. (1989), "Interaction of task and technology to support large groups", Decision Support Systems 5, 139-152.

Nutt, P.C. (1984), Planning Methods, for Health and Related Organizations, Wiley, New York.

NYSID (1988), "A balanced prescription for change: Report of the New York State Insurance Department on medical malpractice", State of New York Insurance Department, 160 West Broadway, New York, NY 10013.

Randers, J. (1977), The Potential in Simulation of Macro Social Processes, or How to be a Useful Builder of Simulation Models, Gruppen for Ressursstudier, Oslo.

Reagan-Cirincione, P., and Rohrbaugh, J. (in press), "Decision conferencing: A unique approach to the behavioral aggregation of expert judgment", in: G. Wright and F. Bolger (eds.), Expertise and Decision Support.

Richardson, G.P., and Schuman, S. (1987), Medical Malpractice Insurance: Policy Implications and Evaluations, Decision Techtronics Group, The Rockefeller Institute of Government, 411 State Street, Albany, NY 12203.

Richardson, G., and Pugh, A. (1981), Introduction of System Dynamics Modeling with DYNAMO, MIT Press, Cambridge, MA.

Richardson, G.P., and Senge, P.M. (1989), "Corporate and statewide perspectives on the liability insurance crisis", in: P.M. Milling and E.O.K. Zahn (eds.), Computer-Based Management of Complex Systems, Proceedings of the 1989 International Conference of the System Dynamics Society, Springer-Verlag, Berlin, 442-457.

Richardson, G.P., Vennix, J.A.M., Andersen, D.F., Rohrbaugh, J., and Wallace, W.A. (1989), "Eliciting group knowledge for model building", in: P.M. Milling and E.O.K. Zahn (eds.), Computer-Based Management of Complex Systems, Proceedings of the 1989 International Conference of the System Dynamics Society, Springer-Verlag, Berlin, 343-357.

Richmond, B. (1987), The Strategic Forum, High Performance Systems, Lyme, NH.

Richmond, B., Peterson, S., and Vescuso, P. (1988), Academic User's Guide to STELLA, High Performance Systems, Lyme, NH.

Richmond, B., and Peterson, S. (1989), STELLAStack, High Performance Systems, Lyme, NH.

Roberts, E.B. (1977), "Strategies for effective implementation of complex corporate models", Interfaces 7/5. Reprinted in. E.B. Roberts, Managerial Applications of System Dynamics, The MIT Press, Cambridge, MA, 1978, 77-85.

Roberts, N., Andersen, D., Deal, R., Garet, M., and Shaffer, W. (1983), Introduction to Computer Simulation: $A$ System Dynamics Modeling Approach, Addison-Wesley, Reading, MA.

Rohrbaugh, J. (1981), "Improving the quality of group judgment: Social judgment analysis and the nominal group technique", Organizational Behavior and Human Performance 28, 272-288.

Rohrbaugh, J., and Andersen, D.F. (1983), "Specifying dynamic objective functions: Problems and possibilities", $D y$ namica 9/1, 1-7.

Schuman, S., and Richardson, G.P. (1987), Medical Malprac- 
tice Insurance: Policy Implications and Evaluations, New York State Insurance Department Policy Development Conferences: Vols I (Conference Results) and II (Technical Appendices), Decision Techtronics Group, Rockefeller Institute of Government, 411 State Street, Albany, New York.

Shachter, R.D. (1986), "DAVID: Influence diagram processing system for the Macintosh", Working Paper, Department of Engineering-Economic Systems, Stanford University, Palo Alto, CA.

Shaw, M. (1932), "A comparison of individuals and small groups in the rational solution of complex problems", American Journal of Psychology 44, 491-504.

Simon, H.A. (1960), The New Science of Management Decision, Harper and Row, New York.

Slater. P. (1958), "Contrasting correlates of group size", Sociometry 25, 129-139.

Sniezek, J.A. (1990), "A comparison of techniques for judgmental forecasting by groups with common information", Group \& Organization Studies 15/1, 5-19.

Stefik, M., Foster, G., Bobrow, D., Kahn, K., Lanning, S., and Suchman, L. (1987), "Beyond the chalkboard: Computer support for collaboration and problem solving in meetings", Communications of the ACM 30/1, 32-47.
Steiner, I. (1972), Group Process and Productivity, Academic Press, New York.

Stenberg, L. (1980), "A modeling procedure for public policy", in: J. Randlers (ed.), Elements of the System Dynamics Method, MIT Press, Cambridge, MA.

Vennix, J.A.M., Gubbels, J.W., Post, D., and Poppen, H.J. (1988), "A structured approach to knowledge acquisition in model development", Proceedings of the 1988 International Conference of the System Dynamics Society, La Jolla, $C A$, The System Dynamics Society, Cambridge, MA.

Vennix, J.A.M. (1990), "Mental models and computer models: design and evaluation of a computer-based learning environment", Ph.D. Dissertation, University of Nijmegen, Nijmegen.

Weil, H.B. (1980), "The evolution of an approach for achieving implemented results from system dynamics projects: Elements of the system dynamics method", Proceedings of the 1976 International System Dynamics Conference, Geilo, Norway, 1976, MIT Press, Cambridge, MA.

Weil, H.B. (1983), "The dynamics of strategy implementation", Dynamica 9/1, 43-47. 